\title{
Investigación de la dominación incaica en Mendoza. El tambo de Tambillos, la vialidad anexa y los altos cerros cercanos
}

\author{
J. Roberto BÁrcena *
}

\section{INTRODUCCIÓN}

En estas páginas informamos sobre el avance de nuestros trabajos arqueológicos en la zona de Tambillos (NO de la provincia de Mendoza, Argentina).

Estos son apoyados por subsidios del CONICET (PID N. ${ }^{\circ} 3-047400$, 1985/87) y del CIUNC (Resoluciones núms. 405/86 y 554/87). Contándose también con la colaboración de otras instituciones y de particulares, todos los cuales comprometen nuestro agradecimiento (Laboratorio de Glaciología - CRICYT Me-, Maestranza y Servicios de la Universidad Nacional de Cuyo, Área de Servicios del CRICYT Me, Área Económico Financiera de la Facultad de Filosofía y Letras de la Universidad Nacional de Cuyo, GAM 8 - Uspallata-, familias Antolín, Jatib, Moroso y Villarroel de Uspallata, familia Zapata, propietaria de la Estancia Los Tambillos -Valle de Uspallata - y "Humberto Giannacari Camping»).

Por su parte, los estudios de gabinete se realizan en dependencias del CRICYT Me - Unidad de Antropología, Área de Ciencias Humanasy de la Facultad de Filosofia y Letras -Instituto de Arqueología y Etnología-, incorporándose los materiales arqueológicos a las colecciones de esta última institución.

* CONICET (CRICYT Me: C.C. 131, 5500 Mendoza). UNC (Fac. Fil. y Letras: C.C. $345 ; 5500$ Mendoza) 
Nuestros estudios sobre el tema incaico en el Norte de Mendoza se remontan a más de una década y dieron lugar a algunas publicaciones ( $\mathrm{J}$. Schobinger y J. R. Bárcena, 1971-1972/73; reed. 1982-, 1972; J.R. Bárcena, 1974 ; etc.) hasta que centramos los trabajos en el estudio general de la vialidad incaica en el NO de Mendoza, según técnicas particulares, prediciendo la existencia de nuevos tambos que finalmente ubicamos y estudiamos (Bárcena, 1977-1979-, 1978, 1977/78-1981-; etcétera).

Luego de esta primera fase de trabajos intensivos sobre el tema, dedicamos nuestro esfuerzo de investigación a la resolución de otros problemas arqueológicos del área (J. R. Bárcena, 1982, etc.; Bárcena y F. A. Roig, 1981/82-1982-; Bárcena, F. A. Roig y V. G. Roig, 1985; etc.).

Por último, en 1983 retomamos la problemática incaica en Mendoza, iniciando trabajos en el tambo de Tambillos.

En esa oportunidad comenzamos el relevamiento topográfico del sitio y excavamos parcialmente algunos recintos en los sectores I y II (fig. 4), con la colaboración activa de los hoy profesores E. M. Guercio, M. P. Ampuero, A. M. Herrera, A. Rodríguez y A. J. Román, que participaron también en los trabajos de gabinete.

Finalmente, luego de una interrupción de las labores por viaje al exterior del suscripto $1984 / 85$, éstas se reanudaron en $1986^{* *}$.

Los estudios se desarrollan ahora en forma paralela con otros sobre la Arqueologia de Mendoza. Sin embargo, se han intensificado de manera tal que permiten esta presentación inicial con los avances del proyecto.

Junto al suscripto, conforma el equipo de investigación la Prof. A. J. Román - colaboradora principal-, los alumnos —carreras de Historia y de Geografía de la Facultad de Filosofia y Letras- Sitas. N. M. Soloa, A. Pacheco, M. Areche, E. Palma, C. Vargas y C. García -Seminario de

** El viaje fue a Europa, con el apoyo del CONICET y de la UN de Cuyo, e implicó una permanencia prolongada en Madrid. En esta ciudad, con lugar de trabajos en el Museo Arqueológico Nacional, tuve la oportunidad de desarrollar un proyecto de investigación sobre el Paleolítico Medio de la Península Ibérica, con la conducción del Dr. Eduardo Ripoll Perelló, en ese entonces Director del MAN.

La cordial acogida, la guía segura y el apoyo continuo, fueron el signo de esta reiación con Ripoll, de quien guardo un recuerdo afectuoso y me precio de su amistad, por to que deseé sumar mi aporte a la excelente iniciativa del presente homenaje. Lo hago con esta primera exposición de una parte de los trabajos regionales reanudados a mi regreso a la Argentina.

Recordaré siempre la bonhomia y enseñanzas del Dr. Ripoll y con él la figura siempre próxima de Doña $\mathrm{A}$. Luisa López de Ripoll, a quien extiendo mi homenaje y con él, a las compañeras de todos los arqueólogos, la otra faz en una esforzada carrera que en buena medida les debemos. 
Investigación de la dominación incaica en Mendoza

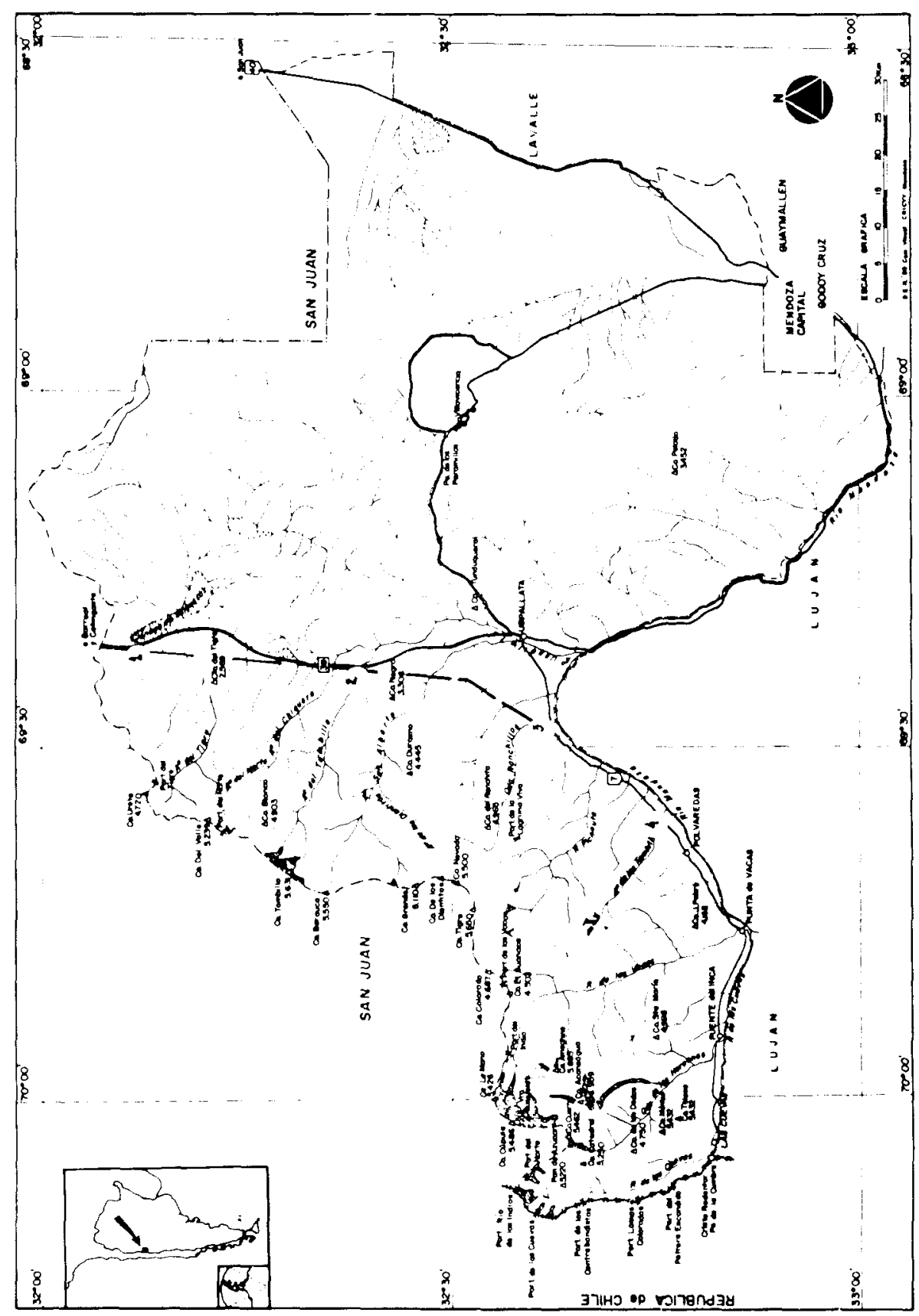

Fig. 1. Plano de la zona estudiada (ct. pág. siguiente). 
Licenciatura de Historia, 1987-, y los Sres F. Seufferheld, P. Rossel, C. Clement, E. J. Ibarra y J. García - Seminario de Licenciatura, 1987-, y el Sr. P. Villarroel -vecino de Uspallata-. Habiendo colaborado también en la primera parte de esta etapa, el Prof. E. M. Guercio y la Prof. V. Fernández.

\section{BREVE EXPLICITACIÓN DE LOS OBJETIVOS Y DE LAS IMPLICANCIAS TEÓRICO-METODOLÓGICAS DE LA INVESTIGACIÓN}

El objetivo general de la investigación es establecer sobre bases arqueológicas el carácter de la ocupación incaica del sector y hasta donde sea posible, avanzar el conocimiento del funcionamiento políticoadministrativo del área durante el incario '.

Habida cuenta de la escasez de fuentes documentales sobre la dominación incaica en Mendoza (G. de Bibar, 1558-1966-, R. de Lizárraga, 1589-1916-, etc.; ver síntesis de C. T. Michieli, 1983: 103-109) es pertinente la profundización de la indagación arqueólogica, en un marco que incluya las posibilidades que brinda la orientación metodológica etnohistórica, sobre la base de la documentación regional citada pero considerando también los avances del conocimiento global de la dinámica socio-

'En las menciones de términos Quechua empleamos indistintamente dos de las formas en uso.

Fig. 1. Croquis del NO. de la provincia de Mendoza. Núms. 1 a 4, posición aproximada de los "tambos" de la Ciénaga de Yalguaraz, de Tambillos, de Ranchillos y de Tambillitos, respectivamente. La línea de grandes trazos, al Oeste del camino provincial $n . .^{\circ} 39$, indica el trayecto aproximado del camino incaico relevado por nosotros. Éste se confunde luego con el trazado de la actual ruta nacional $n .{ }^{\circ} 7$, que nos comunica con Chile. Deberíamos agregar otra comunicación de época incaica -la que aprovecharia muy probablemente una preexistente senda indigena por la Precordillera - entre el Valle de Uspallata y el de Güentota - posiciones de las actuales localidades de Uspallata y de la Ciudad de Mendoza, aproximadamente- También, debió existir otra comunicación del período incaico regional y aún antes, pues ésta provecharía una preexistente, entre los Valles de Güentota y de Uco, éste al Sur del primero. Suponemos también que habia otra comunicación incaica entre el sector de alta montaña del NO de Mendoza - por ejemplo, próximo a la localidad de Punta de Vacas-, con localidades altas de los actuales Departamentos de Luján de Cuyo y de Tupungato (al Sur de Punta de Vacas en el croquis); además de comunicaciones trasandinas al Norte $y$ al Sur del "Paso de Uspallata" (finalmente "Paso de la Cumbre"). 
económica, político-administrativa y religiosa del mundo andino, en particular de los mecanismos reflejados en "horizontes" según los reconocemos desde la vertiente metodológica arqueológica (J. V. Murra, 1970, 1975, etc.; A. M. Lorandi, 1977; J. Hyslop, 1979; etc.). Importa una reconstrucción arqueológica como la que intentamos siempre y cuando podamos imbricarla en una conceptualización mayor que la relacione con el proceso histórico andino, con el carácter particular de la situación extremo austral oriental de la región en el Tawantinsuyu y con las implicancias del propio proceso histórico regional y local.

Por otra parte, partir del estudio de los vestigios arqueológicos senalados, con la intencionalidad anterior, significa también inscribir los trabajos, en una concepción sistémica del Tawantinsuyu, reconociendo los subsistemas de la cultura incaica y en particular el papel de la "red vialasentamientos asociados" propio de la modalidad de expansión e implantación imperial. Es además pensar en cierta estructuración político-administrativa cuya jerarquización denuncian los restos arqueológicos e iluminan los documentos de la conquista y colonización (R. A. Raffino et alii, 1979-82; A. R. González, 1982; etc.).

Debe atenderse también a los avances sobre la comprensión de la conceptualización subyacente en el patrón de asentamiento -ubicación, orientación, disposición general de las estructuras, etc.- sobre los tipos y técnicas arquitectónicas, sobre la funcionalidad diferencial de las estructuras, etc. (R. T. Zuidema, 1966-1968; A. Aveni, 1975, 1981 a y b; P. Krapovickas, 1958-59; C. Morris, 1973, 1974, 1981; J. Hyslop, 1985; R. A. Raffino et alii, 1978, 1981-1982; A. Kendall, 1976; A. M. Lorandi, 1984; etecétera).

Por último, la probabilidad de hallazgos de sitios ceremoniales de altura conlleva adentrarse en una problemática compleja que debe ser abordada también según diversas orientaciones metodológicas (J. Schobinger -edit.-, 1966; J. Reinhard, 1985; P. Duviols, 1986; A. Beorchia, 1984-1987-; etc.)

En la práctica procuramos la representación cartográfica adecuada del trazado del camino incaico en el norte de Mendoza, el descubrimiento y representación de las vias anexas, el conocimiento del tipo y de la distribución espacial de los asentamientos, y de su funcionalidad en relación a la vía de comunicación y al área que se manejaría desde alguno de ellos y, conectado con esto último, el establecimiento de las vinculaciones con otros sitios de asentamiento del período, pero no incaicos.

En esta etapa, como dijimos, centramos los trabajos en el tambo de Tambillos y en la vialidad anexa - entre San Alberto y Yalguaraz-, y en la prospección de altura en zonas próximas del Cordón del Tigre. 


\section{TAMBILLOS}

El sitio ubica a unos $25 \mathrm{~km}$ al norte de la Villa de Uspallata (Dpto. Las Heras, NO de Mendoza), siguiendo el camino interprovincial - $n$. ${ }^{\circ}$ 39- Uspallata-Calingasta (esta localidad es del SO de la Prov. de San Juan) a cuya vera se encuentra. La altitud sobre el nivel del mar es de aproximadamente $2.200 \mathrm{~m}$. (fig. 1).

El tambo se halla en la margen alta - sur- del $A^{\circ}$ homónimo, que en este lugar cruza el camino a Calingasta $y$, en parte, en una elevación del lecho del $A^{\circ}$, entre el actual cauce activo y un canal de actividad ocasional.

No hay datos sobre el sitio en los primeros documentos de la conquista y colonización. Estas fuentes de mediados a fines del siglo XVI y de principios del XVII mencionan sucintamente lo atinente a la dominación incaica regional y se refieren con algún detalle sólo al trayecto entre Mendoza y Santiago de Chile, cuyo itinerario aprovechaba el tramo de camino incaico desde Uspallata hacia el Oeste, por la quebrada del río Mendoza.

La bibliografía especializada moderna tampoco registra mayores aportes sobre el sitio, excepto menciones breves de diferentes autores (F. de Aparicio, 1940; C. Rusconi, 1956: 76 y fig. 26 a., 1962; J. Schobinger, 1971; Schobinger et al., 1971-1972/73-; Bárcena, 1977-1979; J. Hyslop, 1984, etc.).

C. Rusconi reconoció las ruinas primero, ubicándolas sólo en el costado izquierdo del camino a Calingasta, diferenciándolas en tres grupos separados por algunos metros de distancia ("gran cuadrángulo" -que piensa es un corral-, un "grupo numeroso de habitaciones" hacia el Norte del anterior y otro grupo hacia el occidente, ambos a unos $50 \mathrm{~m}$. de distancia del primero). Describe someramente el «cuadrángulo» reconociendo en él una habitación del ángulo nordeste - con abertura de entrada hacia el Este - y aprecia la construcción de los muros mediante doble hilera de piedras. Menciona además dos pequeñas habitaciones próximas al ángulo nordeste dicho. Reconoce, por último, la dificultad de relevar el resto de los grupos de construcciones, ilustrando el "cuadrángulo" y la habitación doble aledaña (Rusconi, 1962: 261 a 263, fig. 316; igual ilustración en 1956: 75-fig. 26 a-) (fig. 2).

Schobinger, por su parte, reitera la división en tres grupos de recintos (habitación de "vigilancia" junto a un "corral de pircas altas", un 


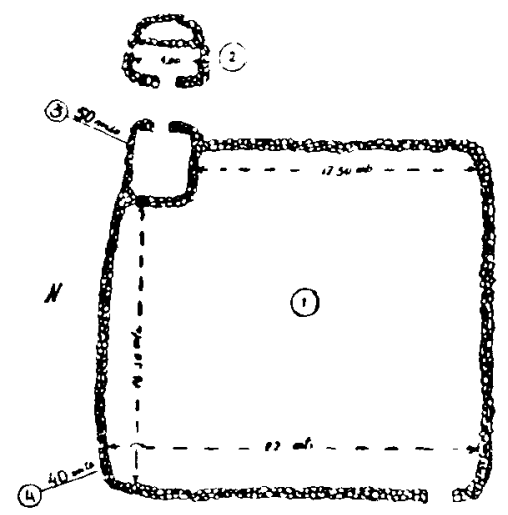

Fig. 2. "Cuadrángulo" y habitación doble aledaña, de Tambillos, según C. RusCONI (1956: 75 -fig. 26 a).

"grupo principal de habitaciones encerradas en un gran rectángulo» - «a unos $80 \mathrm{~m}$. al SO del anterior»- y "uno de habitaciones aisladas del otro lado del cauce", a "unos $100 \mathrm{~m}$. en dirección al norte») (Schobinger, 1971: 80).

J. Hyslop, a su vez, sintetiza los conceptos anteriores y reconoce la dificultad de ubicar con certeza el paso del camino incaico por las ruinas, ubicándolo al Este de las mismas. Observa además la similitud entre el "Cuadrángulo" - «corral?»- de Tambillos, señalado por Rusconi, y la estructura semejante de Ranchillos - tambo al Sur de Tambillos-, y expresa su parecer de que la "divided enclosure" pudiera ser una "kancha-style structure". Menciona por último los daños ocasionados por "bulldozer" en el lugar (Hyslop, 1984: 199).

Finalmente, Schobinger agregó en un escrito dedicado a los sitios ceremoniales de altura, un croquis de la planta del que denominaba "grupo principal de habitaciones encerradas en un gran rectángulo" de Tambillos y que ahora señala como RPC (Schobinger, 1986: 309; croquis basado en un relevamiento de 1964) (fig. 3).

Por nuestra parte realizamos el relevamiento topográfico completo del sitio, empleando teodolito y cinta métrica, fijando en el terreno, mediante estacas, los puntos principales, base de ángulos y mensuras.

A la vez, organizamos la erradicación de la vegetación que había invadido los recintos, con lo que éstos surgieron con mayor nitidez del ambiente circundante sobre cuya vegetación no incidimos. 


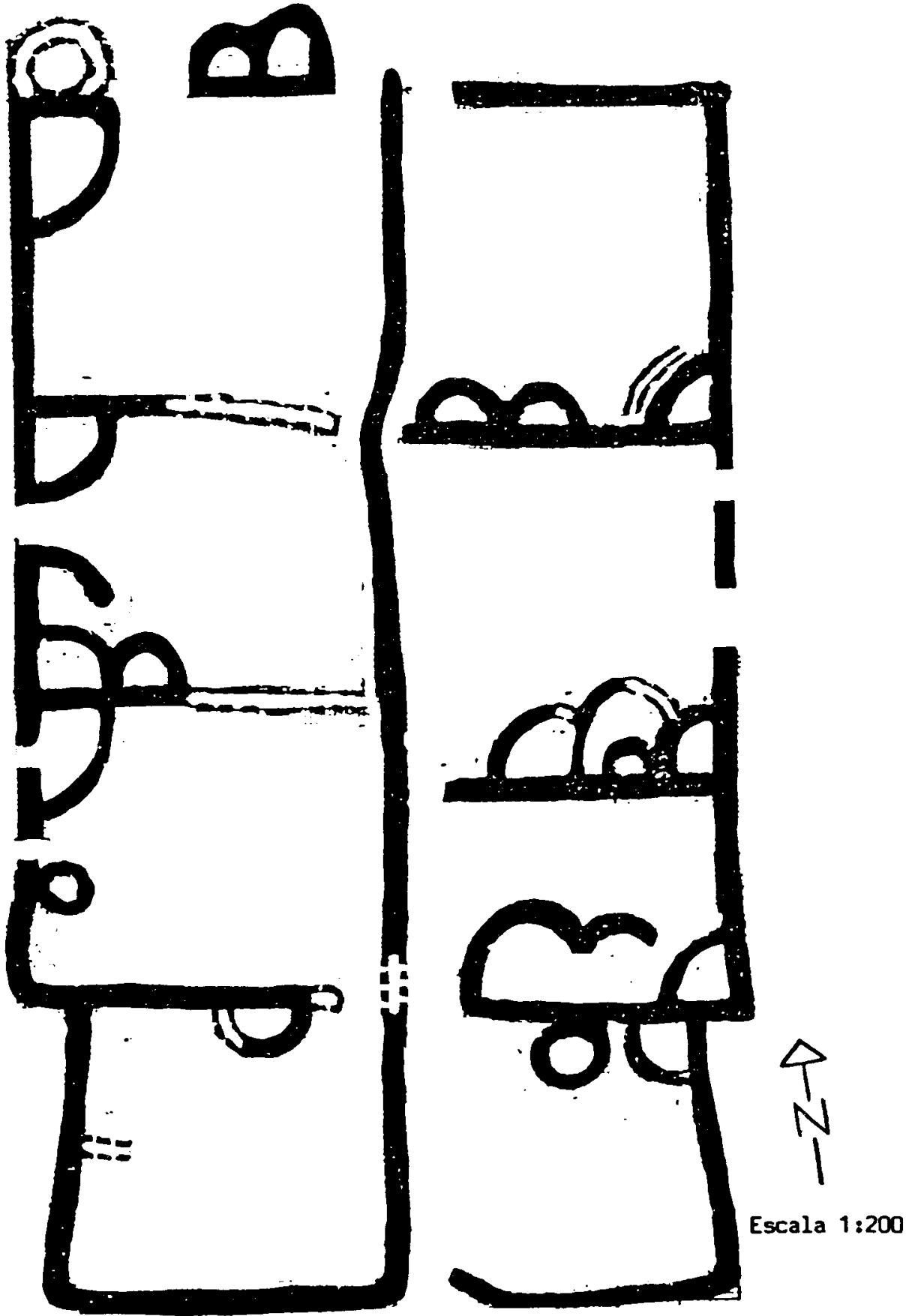

Fig. 3. Rectángulo perimetral compuesto de Tambillos según relevamiento de $\mathrm{J}$. SchoBinger (1986: 309), quien da como dimensiones $41 \mathrm{~m}$. de largo por $24 \mathrm{~m}$. de ancho (ibid.). Nuestras mediciones dieron $49 \mathrm{~m}$. de longitud por $25,40 \mathrm{~m}$. en su ancho mayor y 21,60 en el menor. 
Todo ello permite contar ahora con el plano total del tambo que significa un real avance sobre los intentos parciales anteriores.

Como puede apreciarse en el plano de la figura 4, los grupos de estructuras son más complejos de lo que se pensaba, son más de tres y uno de ellos (un recinto doble) se encuentra al Este del camino a Calingasta (detalle que pasó desapercibido a todos los autores citados). Además, nuestras mediciones comprueban el error de varias de las de Rusconi y de Schobinger (op. cit.). También, nuestra reconstrucción del trazado del camino incaico, según una técnica que hemos descrito anteriormente (Bárcena, 1977-1979-: 664/666), permite ahora saber con certeza que si bien ingresaba al tambo al Este de los grupos de estructuras señaladas por los otros autores, pasaba en realidad al Oeste de un sector del grupo más nórdico (si es que mantenemos la división en tres grupos al Oeste del camino a Calingasta y agregamos un cuarto al Este del mismo) (nosotros preferimos considerar tres sectores: I, II y III en el plano de figura 4).

Por otra parte, reconocemos una situación altitudinal entre los grupos de estructuras (tenemos las diferencias de nivel, que se representarán según curvas en otro plano) que manifiestan una clara jerarquización entre ellas. También la clásica "kancha"-RPC--, primera en la jerarquía arquitectónica del sitio, muestra su tendencia a la forma trapezoidal y se acerca - aún en la mensura - al patrón de la existente en Ranchillos, según puede apreciarse en los planos de Aparicio (1940; plano de 1937 del Ing. A. Milou) y de Rusconi («sector IV», 1956 y 1962; relevamiento casi coétaneo con el de Aparicio) (fig. 5 a y b; fig. 6 a y b).Aunque en el caso de Ranchillos la escala de la jerarquía de estructuras comienza por la clásica construcción de habitaciones - con corredor perimetral-y de patios inscriptos en un rectángulo pircado (sector 1 -y sector II?- - de Rusconi, 1956, 1962) y continúa, a nuestro juicio, por la estructura ya señalada, similar a la de Tambillos. Esto conduce a uno de los caminos de verificación de hipótesis sobre la distinta significación de ambos sitios, de la jerarquización entre ambos y del particular rol de Ranchillos en la ocupación incaica local ${ }^{2}$ (fig. 7).

También es sugestiva la similitud de la citada estructura "cuadrangular» de Rusconi —en Tambillos - con la del «sector XIl» de Ranchillos

2 También en Tambillitos (fig. 1), tambo que relevamos y estudiamos hace tiempo ( $\mathrm{J}$. SCHOBINGER Y J. R. BÁRCENA, 1971 - 1972/73-; J. R. BÁRCENA, 1977-1979-), encontramos un "RPC" de mayores dimensiones, cuya planta guarda alguna similitud con las referidas de Ranchillos y de Tambillos. 


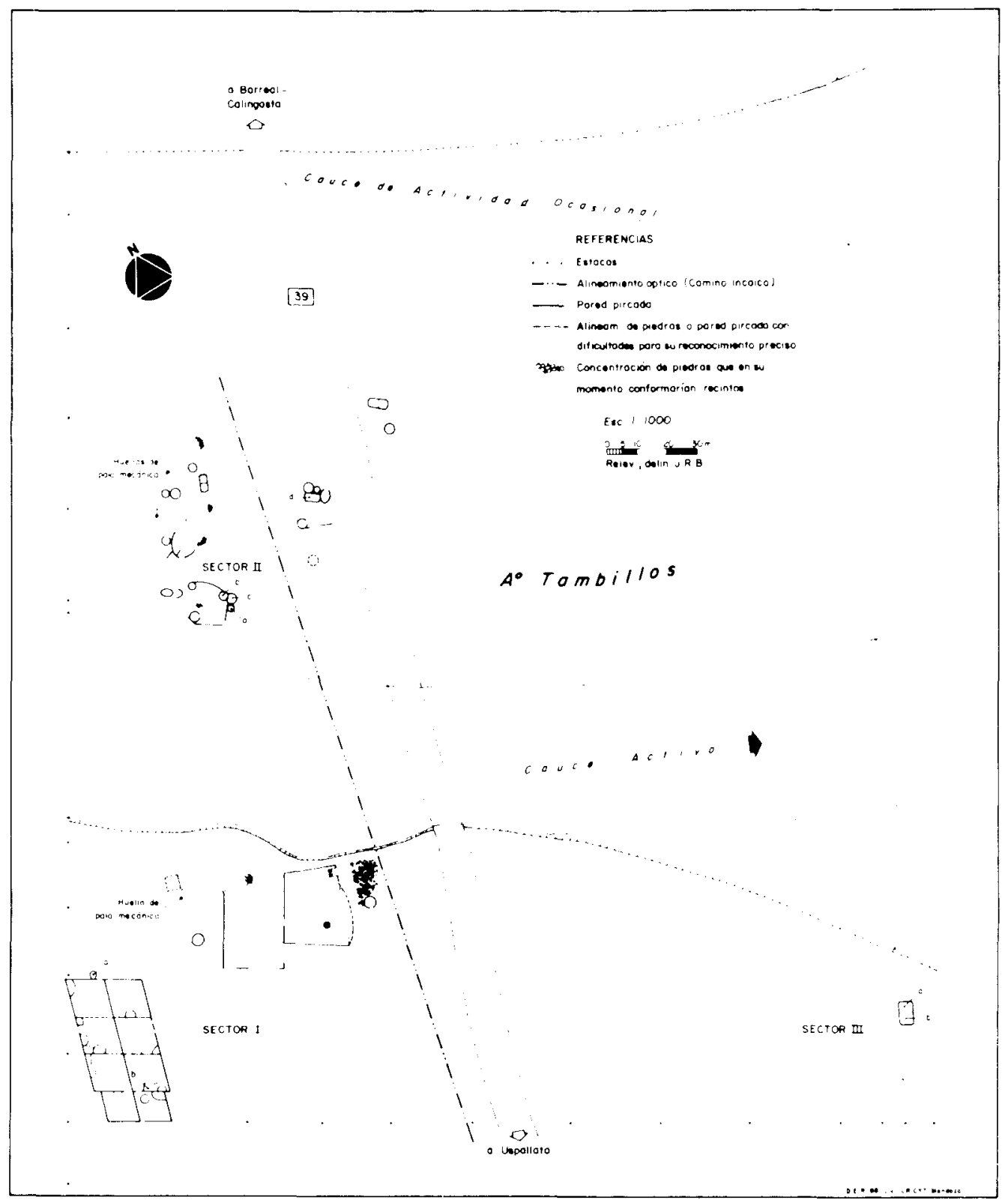

Fig. 4. Tambo de Tambillos según nuestro relevamiento. Aprox. 2.200 m.s.n.m., NO de la Provincia de Mendoza -Argentina-. 


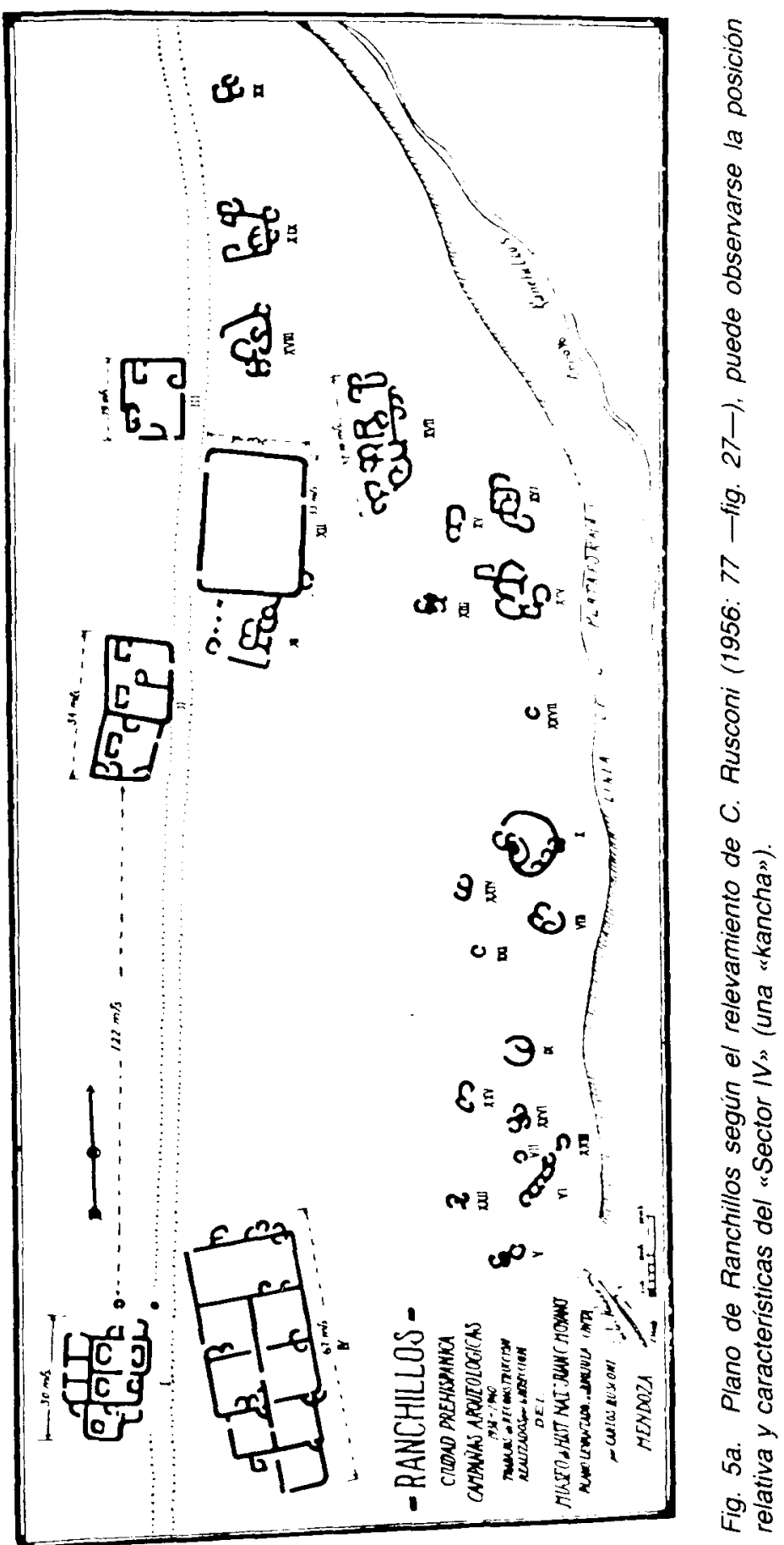




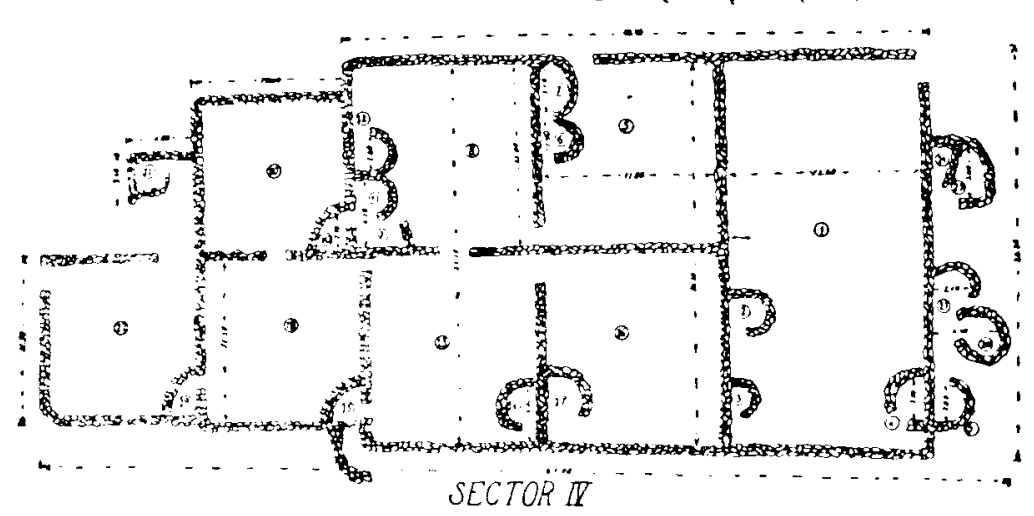

Fig. 5b. Detalle del mismo "sector IV" según C. Rusconl (ibid.: 67 -fig. 3-).

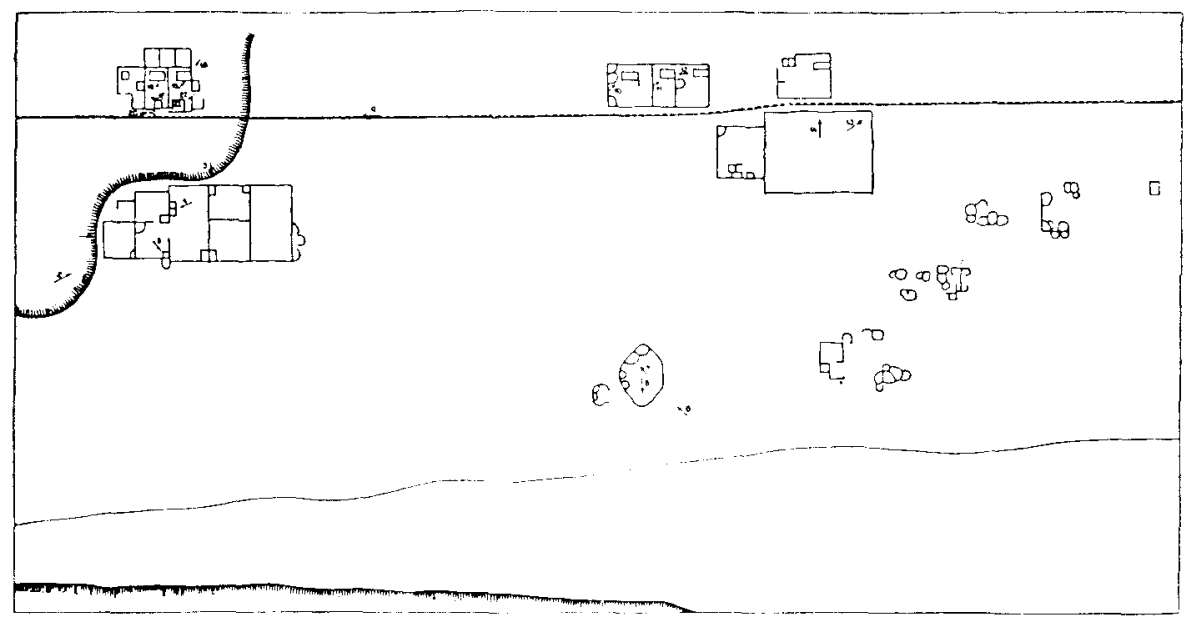

Fig. 6a. Plano de Ranchillos según el relevamiento del ing. A. Milou (en F. de ApARICIO, 1940: 251 -fig. 2-), donde se observa también el RPC señalado en fig. 5, con el agregado de la situación altitudinal de la estructura, que nosotros reputamos como significativa en la jerarquia arquitectónica del sitio y comparamos con la de Tambillos y, más recientemente, con la similar de Tambillitos.

-representada y designada asi por el mismo autor, op. cit-, como lo señala Hyslop preguntándose si es un "corral" (op. cit. 199) (figs. 2 y 5a).

Nuestro relevamiento de ese sector de Tambillos ( 1 en fig. 4 y fotografía aérea de fig. 8) muestra un espacio trapezoidal pircado al que se 


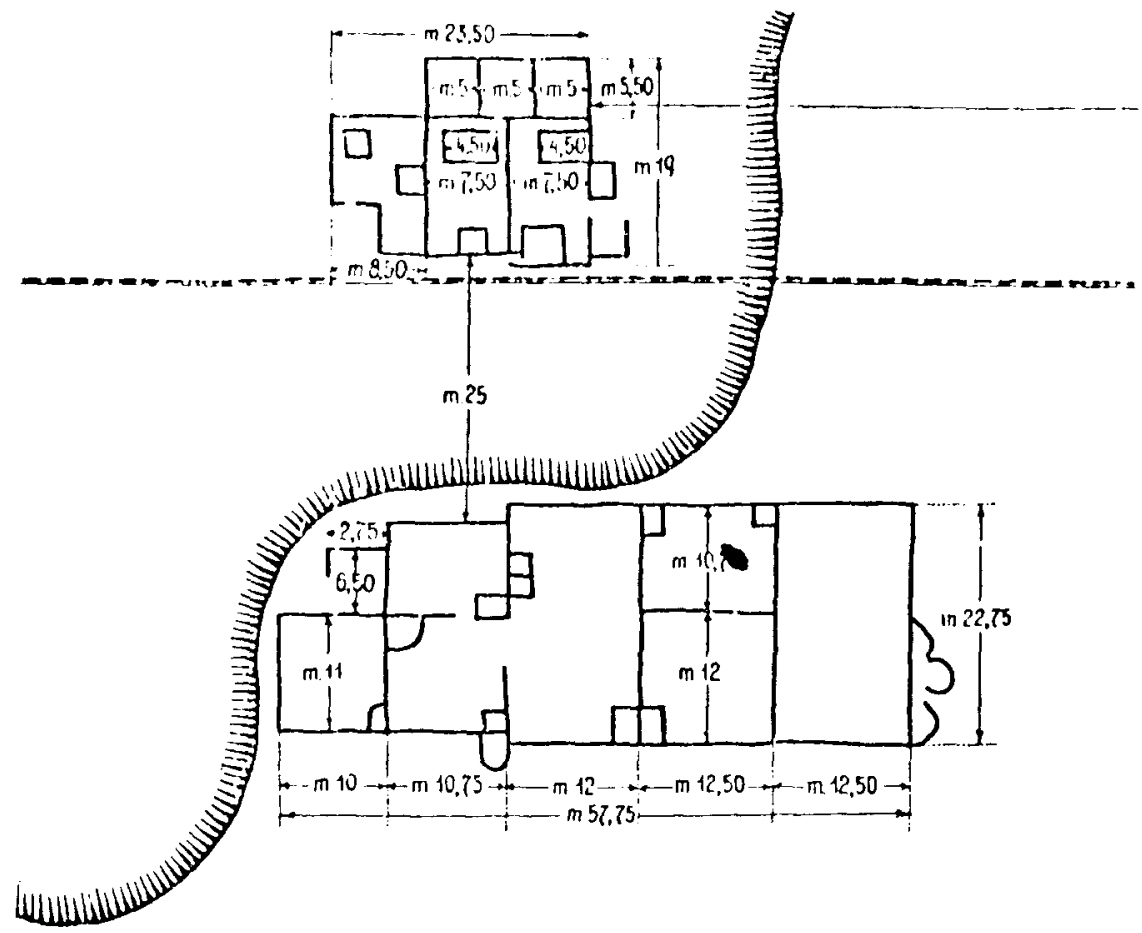

Fig. 6b. Detalle del plano anterior con el RPC (abajo) objeto de las comparaciones (ibid.: lámina desplegable intercalada).

accede por dos aberturas, una de las cuales en lugar de la pirca con salida hacia el Este, como señaló Rusconi -1962: 263 y figura 316; 1956, fig. 26a-, parece consistir en una escalinata de dos o tres peldaños. (Las próximas excavaciones en este lugar dilucidarán ese aspecto).

Nuestra hipótesis de trabajo es que éstos no son corrales sino las características plazas "intramuros" — «amuralladas"- de las instalaciones inca (ya Rusconi efectuó una consideración parecida para la estructura de Ranchillos -1956: 70, 1962: 247-, retomada sobre bases contextuales más sólidas por Raffino et al. -1981 (1982): 114-).

Otra comprobación sugestiva -inscripta metodológicamente en una línea de investigación seguida por autores como Zuidema, Aveni, Hyslop, etcétera (op. cit.)-- fue encontrar que los muros del recinto doble (aislado) -sector III en fig. 4- están orientados entre $1^{\circ}$ y $2^{\circ}$ al Sur de la cumbre del $\mathrm{C}^{\circ}$ Tambillos - cumbre mayor del Cordón del Tigre, al Oeste de las ruinas - y con una elevación mayor de la Sierra del Tontal, que se aprecia en el horizonte N-NE (muros Sur y Oeste de la estructura, 


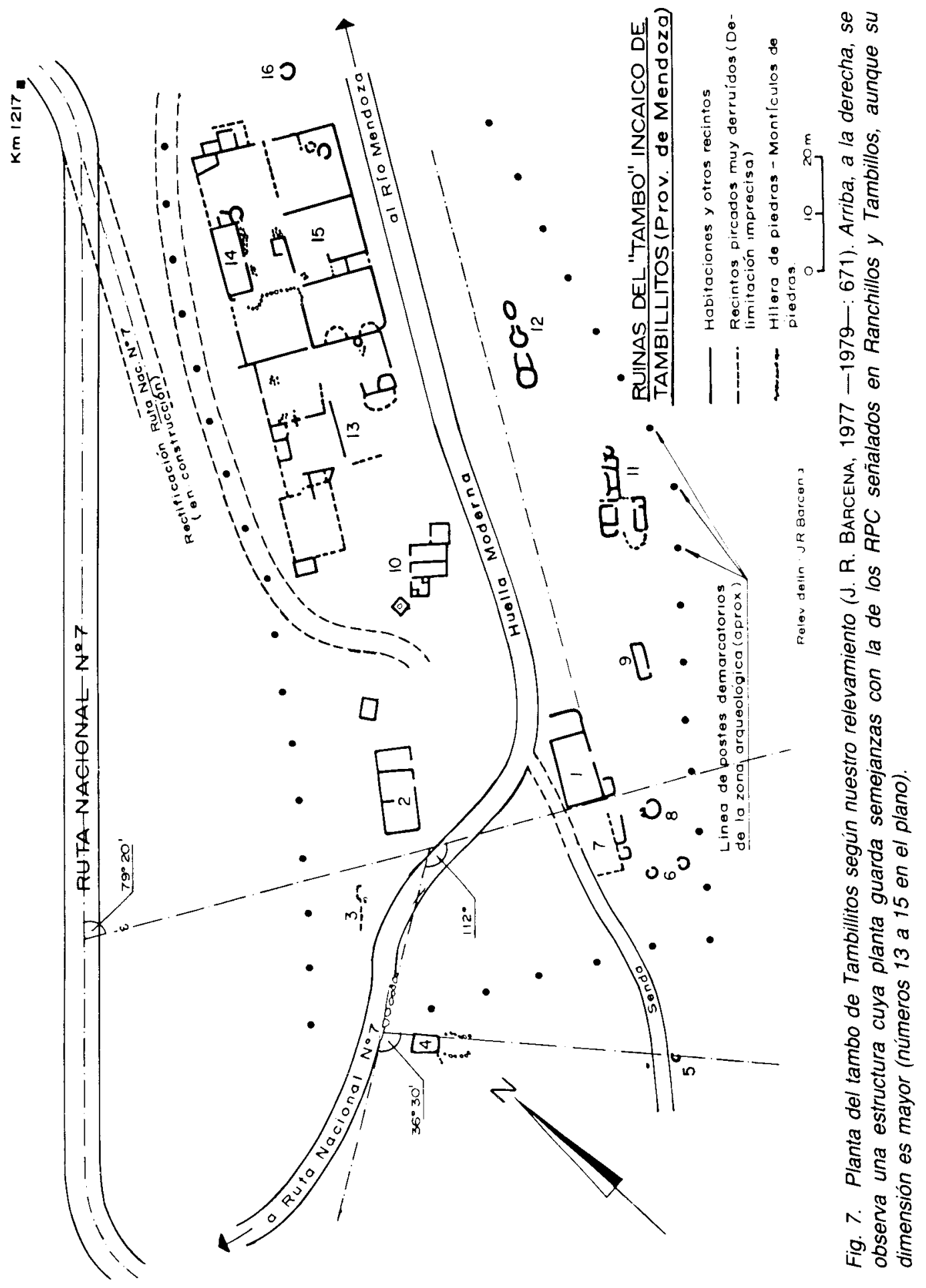




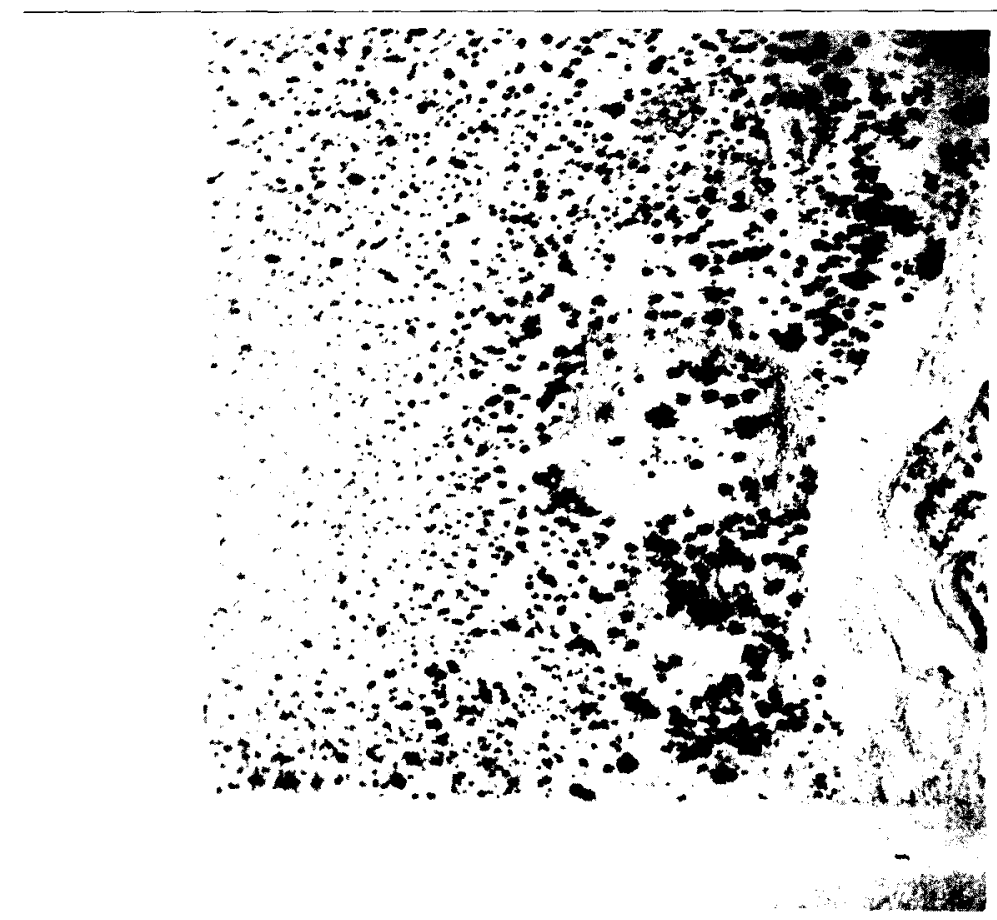

Fig. 8a. Fotografia aérea, mediante un sencillo y económico dispositivo accionado por control remoto, del "Cuadrángulo" según Rusconi, "corral" según otros, o "plaza intramuros" - -amurallada»- según nuestra opinión, del tambo de Tambillos. En el ángulo superior izquierdo se aprecia, en sombras, parte del RPC. Abajo, de Sur a Norte -izquierda a derecha- se observa el camino a Calingasta (fig. 4) y, reuniéndose con él, el A. Tambillos. Hacia el Oeste de la estructura pircada, se observa la huella de una "pala mecánica".

respectivamente). Si a esto agregamos que hacia el 21 de septiembre el sol se pone prácticamente tras la cima del $\mathrm{C}^{\circ}$ Tambillos, tenemos suficientes elementos para justificar, profundizar con esta perspectiva e intentar el aporte interdisciplinario desde los estudios astronómicos.

En relación con los trabajos de relevamiento desarrollamos una técnica de fotografía aérea con resultados satisfactorios. Nos basamos en un dispositivo simple que en su oportunidad nos mostró el investigador J. Hyslop

El dispositivo consiste en una cámara fotográfica automática, de determinada relación tiempo de exposición-sensibilidad de la película, montada en un sistema cardánico, suspendida de un globo cautivo -inflado con gas hidrógeno- y accionada por control remoto (técnicos del CIDEM colaboraron con nosotros en lo concerniente al cálculo del "empuje» 


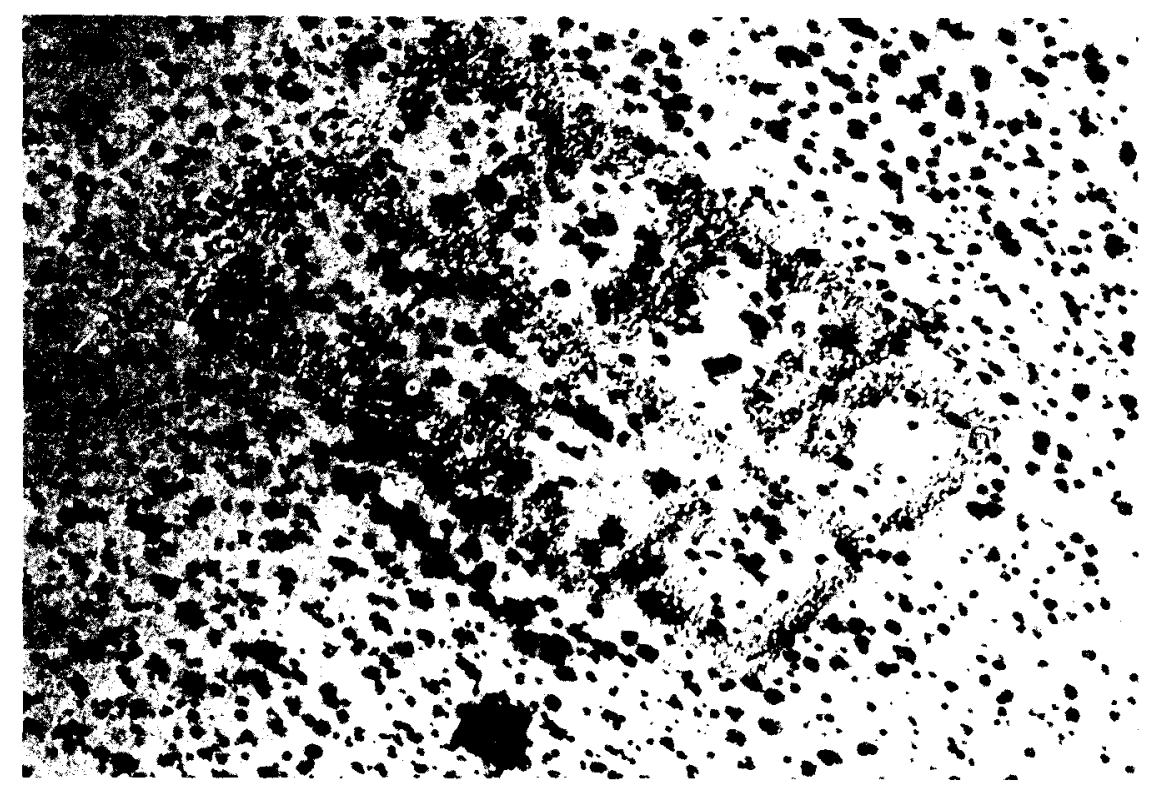

Fig. 8b. Fotografia aérea con igual técnica que la anterior, donde se observa una toma de menor altura del RPC de Tambillos. El "punto" en la esquina sudoccidental (ver fig. 4) del RPC, la "linea" $y$ el "circulo" del interior, blancos, son marcas en el terreno utilizadas como referencia. La estructura más oscura, al occidente del RPC, es nuestra carpa de trabajo.

-relaciones entre masa, gravedad, resistencia atmosférica y el volumen del globo/masa del gas utilizado-; mientras que técnicos del Departamento de aerofotogrametría de la Dirección Provincial de Catastro, hicieron lo propio respecto al cálculo de escalas).

Las fotografías obtenidas en Tambillos muestran las buenas posibilidades de esta técnica en usos arqueológicos (ver fig. 8). En este caso particular fueron útiles para la confección del plano y para la comprensión general de la situación del conjunto arquitectónico.

El tambo de Tambillos se encuentra en malas condiciones de conservación, no sobrepasando las paredes de sus estructuras los 0,50 m. de altura. Su deterioro se debe al transcurso del tiempo y, en buena medida, a la acción de máquinas "topadoras" que se usan para mantener el aledaño camino interprovincial (ver sus «huellas» en el plano de fig. 4). Se aprecia además la acción de "huaqueros" que han excavado en algunos lugares. 
Pensamos que nuestra labor podría ir más allá de la investigación científica y comunicación al medio idóneo, por lo que proyectamos una forma accesible de transferencia al medio. Ésta la canalizamos a través de una propuesta a la Subsecretaría de Cultura de la Provincia de Mendoza, que se interesó por el proyecto desde la Dirección de Patrimonio, Museos y Biblioteca.

Nuestro esfuerzo se dirige a lograr el acondicionamiento de los recintos según pautas elementales de conservación, un cierre perimetral del lugar, la instalación de una estructura-mirador (desde la que se observe mejor el RPC, el camino incaico y el panorama de la cordillera nevada) y de carteles explicativos, y a la confección de un folleto de difusión sobre las características del incario en el área $y$, en particular, sobre Tambillos. (Con el auxilio del Laboratorio de Ambiente Humano y Vivienda del CRICYTMe se diseñó - C. de Rosa- y calculó - E. Japazla estructura-mirador, cuya fundación ya efectuamos).

Volviendo a las investigaciones en Tambillos debemos referir nuestro estudio de las técnicas arquitectónicas. Apreciamos muros construidos con hileras dobles de piedra que, en especial en el RPC - sector I, fig. 4- han sido canteadas - "simil sillares»-, están unidas con argamasa y provienen de una formación rocosa cercana. No obstante, en la mayor parte de las construcciones se registran pircas formadas con cantos del arroyo anexo. Pensamos que una parte de las piedras trabajadas de Tambillos fueron retiradas del lugar y pasaron a formar parte de las construcciones del casco de la Estancia homónima actual (a unos $5 \mathrm{~km}$. al Oeste del lugar; en cuyos terrenos está Tambillos).

Por otra parte hemos excavado ya ocho recintos (sector $\mathrm{I}$, a y $\mathrm{b}$; sector II, a, b, c y d; sector III, a y b; ver fig. 4) con la mira puesta en la inferencia de funciones específicas y con ella en el establecimiento de la funcionalidad diferencial general del sitio.

En los recintos de los sectores I (a) y II (a, b y d) identificamos el piso original, arcilloso consolidado, de las que fueron habitaciones con fogones centrales y materiales asociados que reflejan actividades económicas de preparación de alimentos, etc. El recinto $\mathrm{c}$ del sector II, por su parte, parece corresponderse con los anteriores, sin embargo presenta una complejidad particular, cuya resolución está en curso.

Los recintos del sector II evidenciaron dos niveles nitidos de ocupación, lo cual introduce nuevas perspectivas en el estudio de un sitio que se supone producto de la ocupación durante un reducido número de años (aprox. 1480-1536 A.D.; cf. Bárcena, 1982: 77 —infra-). 
Por su parte, el recinto b del sector I presentó una particular disposición constructiva, revelada por la excavación, que nos hace suponer una funcionalidad relacionada con el almacenamiento ("collica").

La excavación del recinto doble del sector III mostró algunas particularidades constructivas (muros dobles con distinta técnica y esquinas redondeadas) y que la división en dos recintos sin comunicación correspondia en realidad a una época posterior a la primera ocupación del lugar. En verdad, parece posible discernir tres momentos de la ocupación del recinto, que sufrió sucesivas transformaciones. El primer momento correspondería a indígenas de "tradición local» (fases del tipo "Viluco" - H. A. Lagiglia, 1977/ 1979 - o del “Complejo cultural Aconcagua»- E. Durán S. y M. Massone M., 1977/1979, 1979/1982; M. Massone M., 1980; R. Stehberg L., 1981-; etc.), que han asimilado elementos de la cultura incaica.

Un fechado radiocarbónico, resultado del tratamiento de una muestra proveniente de un leño semiquemado hallado en el piso inicial de la ocupación del recinto Norte (a) del sector III, dio $770 \pm 50$ años A.P. (1180 \pm 50 A.D.; Beta-25221), sugiriendo su correspondencia con una primera ocupación del lugar por indígenas de la región ${ }^{3}$.

Con la excavación de los recintos del sector III discernimos pisos consolidados arcillosos, varios fogones en ellos, restos óseos de auquénidos y de aves (quemados o no), puntas de proyectil (pequeñas, triangulares isósceles, de base escotada, en variedades de cuarzo), fragmentos de valvas de molusco - quizás marinos-, cuentas de collar, artefactos de pizarra (probables pulidores-alisadores para cerámica), fragmentos de arcilla y de "piedra pómez", fragmentos de grandes vasijas (borde y cuello de aríbalo - decorado-, gran base de cerámica tosca -con "torus" marcado-, etc.), etc.

Por todo ello, en especial por los numerosos pulidores - alisadores para cerámica- de acuerdo con nuestro estudio tipológico (Bárcena y A. J.

${ }^{3}$ El resultado corresponde por supuesto a la fecha de la madera y no a la efectiva de la ocupación. Para contrastarlo efectuamos un nuevo análisis radiocarbónico, esta vez sobre carbón de un fogón de la ocupación inicial en el recinto Sur (b), que dio una antigüedad de $410 \pm 70$ A.P. (Beta 26283), coincidente con el periodo de dominación incaica regional. Hoy no tenemos dudas sobre la utilización de la estructura, desde el inicio, por el inkario y de su funcionalidad especifica - manufactura cerámica- También, hipotetizamos sobre la presencia de mitmaq locales -o regionales - al servicio de la organización estatal incaica - "sañucamayoc"-, supervisados, quizás, por maestros artesanos - "sañucamayoc" o bien algún «tocricamayoc"- extraños a la región -de la Cuenca Sur del Titicaca ?-. (J. Roberto Bárcena y Alicia J. Román, 1988; comunicación presentada en el IX Congreso Nacional de Arqueología Argentina-Buenos Aires, 31 de octubre al 5 de noviembre de 1988 , "Resúmenes", pág. 88). 
Román, 1988) y la comparación con datos bibliográficos (G. Ampuero B., 1969; E. M. Cigliano -edit.- 1973; etc.) y por su relación contextual, sugerimos que la utilización de este sector (III) de Tambillos fue para la manufactura de cerámica —en particular grandes recipientes, adecuados para almacenamiento-, por artesanos regionales según patrones incaicos.

La particularidad del sector III es sugerida además por el hallazgo de algunos fragmentos de cerámica —partes de un plato (¿ornitomorfo?)- que se corresponden con la denominada "Inca Pacajes" (o Saxamar en el Norte de Chile - región de Arica-), atribuida a los Pacaxes del altiplano boliviano -al Sur del lago Titicaca--, en la época en que estuvieron sujetos a la dominación incaica (cerámica con engobe rojo y "llamitas" estilizadas pintadas en negro - especialmente forma de platos-).

El hallazgo de este tipo cerámico admite diversas interpretaciones. Sin embargo, preferimos por ahora remitir a las consideraciones de otros autores sobre el tema ("Relaciones Geográficas de Indias", t. II, p. 5164, 1985 -siglo xvI—; S. Ryden, 1947; C. Munizaga, 1957; M. Segovia A., 1959; P. Dauelsberg, 1961-1972; P. Krapovickas, 1958-59; H. Niemeyer F., 1963-1964; J. Iribarren Ch. y H. Bergholz W., 1972; A. Llagostera Martínez, 1976; R. A. Raffino et alii, 1981-1982; etc.), señalando la novedad de esta cerámica en el registro arqueológico de nuestra región.

El mismo sector (III) mostró también uno de los dos objetos no indígenas hallados hasta ahora en el tambo. Se trata de un fragmento de loza subactual, hallada en una posición que inclina a considerarla intrusiva.

En general, la cerámica exhumada por las excavaciones y la proveniente de recolecciones superficiales en el tambo (éstas se hicieron diferencialmente) arrojó porcentuales próximos respecto del número de fragmentos no decorados y decorados (incluyendo en éstos a los engobados). En ambos casos las proporciones rondan el 40 y 60 por 100 , correspondiente a fragmentos decorados y no decorados, respectivamente. Porcentuales cercanos a los ya señalados para otros sitios incaicos del área (Bárcena, 1977-1979; E.E. Berberián et al., 1977/78-1981).

Los tipos cerámicos no decorados corresponden a fragmentos de cerámica tosca, de superficie interna y externa alisada, de color gris o marrón - hay algunos fragmentos incisos- $y$, en forma mayoritaria, de superficie alisada color "rojo ladrilio" (un tipo común con los de tambos que ubican al Norte de Tambillos - Ciénaga de Yalguaraz y Leoncito-). Los tipos decorados presentan engobe rojo en una o en ambas superficies, a veces con motivos de decoración pintados en negro -en bordes o en fragmentos de cuellos o de cuerpos de vasijas-, o bien con engobe blanco en una de las superficies - decorado, a su vez, o no, con motivos pintados de color negro-. Otros motivos de la decoración combinan el 
rojo, el blanco y el negro, constituyendo cualquiera de los dos primeros el color base (engobe).

Las formas que predominan se corresponden con platos -probablemente con apéndices ornitomorfos-, ollas, aribalos, aribaloides, etc. En el caso del sector III (ambos recintos) sobre más de 500 fragmentos de cerámica recuperados obtuvimos un promedio de espesor de paredes próximo a los $7 \mathrm{~mm}$., sugestivo respecto del tipo de vasijas existentes allí.

Tanto las formas como la decoración apuntan a tipos que usualmente designamos como incaicos, aunque una parte de los fragmentos decorados se asimilan por sus motivos al llamado "diaguita chileno" - «Coquimbo polícromo" según algunos autores- («diaguita de influencia incaica" de H. Niemeyer F., 1969-70; "diaguita III", "fase III" O "diaguita incaico" de G. Ampuero B., 1977-78, 1978; etc.).

Estos restos reafirman la hipótesis de la ocupación por Mitmakunas del Norte Chico chileno que, por otra parte, ahora vislumbramos más allá de los límites estrictos de los tambos del NO de Mendoza (hallazgos en la Precordillera y en la porción Sur de la Cordillera Frontal).

Otro aspecto importante, que estamos estudiando, es el de la relación con la población local. Es evidente que varios de los tipos cerámicos se corresponden con los propios de la denominada "Cultura de Viluco" (relacionada a su vez con el "Complejo Cultural Aconcagua", de Chile central). Como expresamos, los recintos del sector III del tambo representarian con mayor nitidez el contacto $y$, aún, la preexistencia de un grupo local en el lugar.

\section{CAMINO INCAICO}

El estudio del mismo se orienta en dos sentidos. Uno, primordial, que apunta a la precisión del tramo principal en el Norte de Mendoza y SO de San Juan $-y$ al reconocimiento de ramales secundarios-; y el otro, derivado del primero y en estrecha relación con el mismo, que consiste en "marcar" el camino procurando "fijar" una vía que en algunos trechos puede desaparecer en el futuro.

Ya explicamos la técnica que aplicamos en el reconocimiento del tramo principal del camino y en su «fijación" (Bárcena, 1977-1979). Sin embargo, recordamos la utilización de medios ópticos (teodolito), cinta métrica y brújula; la determinación de direcciones, orientación respecto al Norte y diferencias de nivel. Como expresamos, esperamos representar 
en forma cartográfica un trazado pormenorizado y ofrecer un perfil altitudinal del camino.

Ahora, en esta etapa de trabajos, relevamos en forma metódica el sector San Alberto (desde un punto al pié del $C^{\circ}$ Negro)- $A^{\circ}$ del Tigre. Esto permitió ubicar con precisión el paso del camino incaico por Tambillos -como dijimos- y fijar estacas -equidistancia aproximada $1 \mathrm{~km}$.hasta unos $500 \mathrm{~m}$. al Norte del tambo (fig. 1y 4).

Continuamos comprobando la utilidad de la técnica de relevamiento y proseguimos verificando nuestra hipótesis sobre la presencia de cerámica del período incaico a lo largo del camino.

Si pensamos en el sistema total del incario y en el fundamental aflujo de energía" por sus vías de comunicación, debemos pensar también que los vestigios arqueológicos en ellas deben consistir en algo más que en restos arquitectónicos.

Con este criterio extremamos el cuidado en la prospección del camino, hallando una y otra vez la cerámica característica.

Sin embargo, el número de fragmentos no es tan numeroso como para permitir aún inferencias sobre, por ejemplo, la proporcionalidad de los tipos característicos que podrían indicar aspectos de la utilización del camino. Por otra parte, la concentración de fragmentos de algunos lugares indicaria otras posibilidades ("postas", lugares de concentración de "operarios", etc.).

Con los trabajos en el sector San Alberto-Tambillos constatamos que en varios lugares y a ambos lados del camino-particularmente al sortear cauces secos, con abundantes cantos existe un muro bajo o hilera de piedras (el ancho de la vía oscila, en varios tramos del sector entre 5 y $6.5 \mathrm{~m}$ ) e, incluso, en un cauce con cierta dificultad de paso se aprecian los que aparentan ser tres escalones (fig. 9).

\section{PROSPECCIONES DE ALTURA}

Con el criterio expuesto al comienzo postulamos la existencia de sitios ceremoniales -del periodo considerado- en las alturas próximasal tambo de Tambillos. Estas pertenecen al Cordón del Tigre - una parte de la Cordillera Frontal-, donde destaca el $\mathrm{C}^{\circ}$ Tambillos -aprox. 5600 m.s.n.m.- El mencionado Cordón no había sido indagado antes con esta perspectiva. 


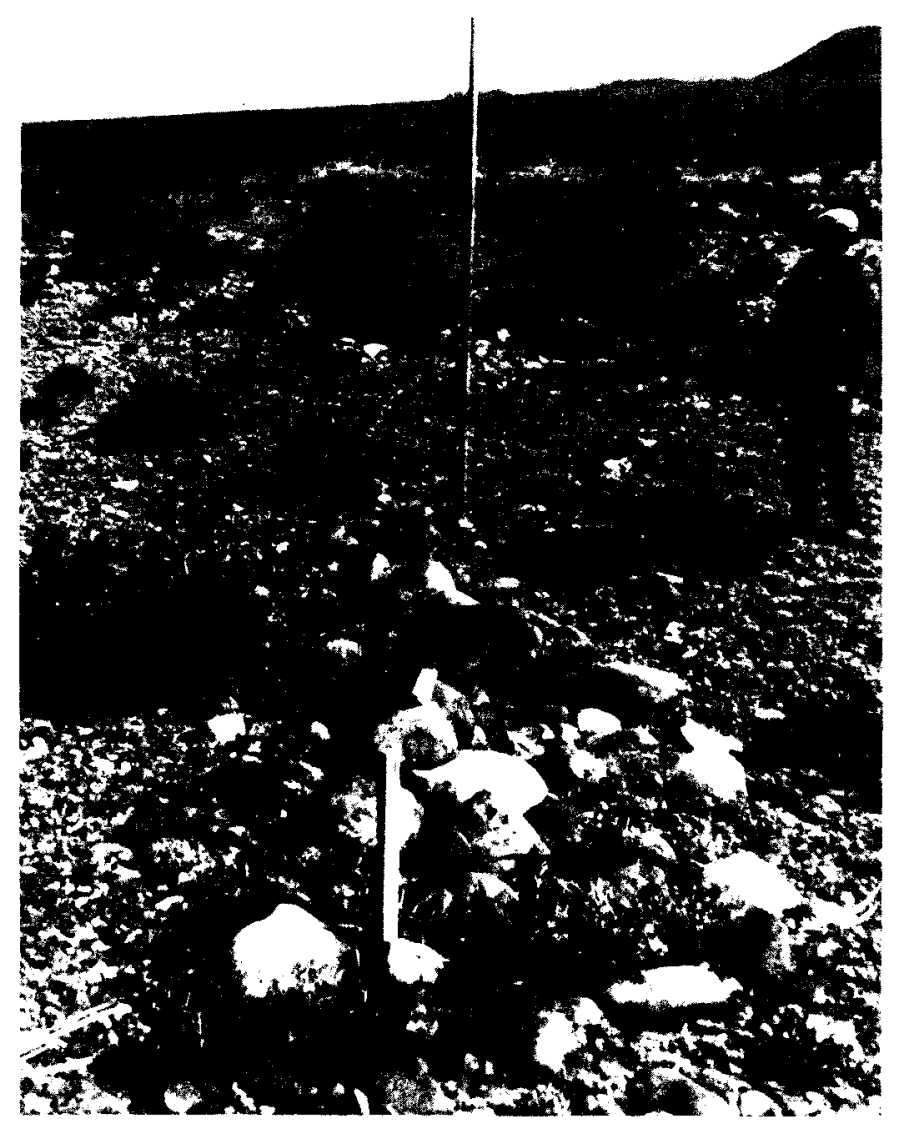

Fig. 9. Vista del camino incaico hacia el Sur, en un sector proximo al tambo de Tambillos. En primer plano restos de uno de los muros pircados -o hilera de piedras-que lo limitaban.

Primero prospectamos el Cordón de los Tambillos tratando de ubicar una pirca de altura, de la que teníamos noticia por nuestro colaborador Sr. G. Antolín - fallecido hace unos años-. Conseguimos localizarla en el verano de 1986.

Se trata de un recinto pircado con materiales producto de la intensa criogenización de la formación sobre la que está construido - pirca rec-tangular, de 2,3 $\times 3,5 \mathrm{~m}$., cerrada por tres lados (el cuarto corresponde a la ladera del cerro), a aprox. 3.750 m.s.n.m.

El lugar es inhóspito («Portezuelo de la Ciénaga del Sol») y la cons- 
trucción no se corresponde, por su ubicación y técnica, con las usuales de los moradores modernos de la zona.

No hay indicios arqueológicos (excavamos en varios sectores sin resultado positivo). Sólo hallamos en el ángulo NO, en superficie, restos de un tronco cuyo extremo estuvo expuesto al fuego.

Las características de la pirca, su situación en el paso y próxima al $\mathrm{C}^{\circ}$ Tambillos, y la existencia de un leño semiquemado - de madera que proviene de un piso altitudinal 300 a $500 \mathrm{~m}$. más bajo-, nos indujeron a plantear la hipótesis de su origen indígena y de su relación con posibles sitios ceremoniales en las alturas cercanas.

La madera fue determinada en el Laboratorio de dendrocronología del CRICYTMe como perteneciente a un ejemplar de Adesmia sp. («acerillo"), de unos 150 años. También, tomamos una muestra de los anillos correspondientes a los primeros 10 años del ciclo vital, la que está en proceso de datación $14 \mathrm{C}$ en el INGEIS ${ }^{4}$.

Basándonos en los datos e hipótesis anteriores organizamos un equipo para las prospecciones de altura en el que integramos varios andinistas del Club Universitario de andinismo (CUDA), que también son alumnos de los Departamentos de Historia y de Geografía de la Facultad de Filosofía y Letras, de la Facultad de Ingeniería y del INEF.

A comienzos de 1987 prospectamos nuevos sectores del Cordón de los Tambillos hasta el pié del $\mathrm{C}^{\circ}$ homónimo e hicimos lo propio con una de las vías que llevan a la cumbre de ese cerro, la que se logró en febrero de ese año (Seufferheld-Rossel, grupo de apoyo Bárcena-F. Norton). Posteriormente, hicimos algo similar con el $\mathrm{C}^{\circ}$ Barauca (unos 5300 m.s.n.m., al SO del anterior; cumbre lograda por los mismos andinistas, grupo de apoyo G. Moroso-P. Villarroel) y aún, con un cerro que corona un filo de menor altura y próximo al $\mathrm{C}^{\circ}$ Tambillos (al SE de éste) que denominamos LIRA (unos 5.000 m.s.n.m.; cumbre por Seufferheld-lbarra).

De estos trabajos no surgió la identificación de vestigios arqueológicos de altura, que en el caso del $\mathrm{C}^{\circ}$ Tambillos bien pueden estar cubiertos por el enorme glaciar que se desarrolla desde su cumbre.

Para completar las labores, decidimos seguir otra ruta hacia la cima del Tambillos. Esta vez - verano 1988- partiendo de la pirca de altura, siguiendo un filo próximo que conduce a dos cimas menores del Tambillos.

\footnotetext{
${ }^{4}$ Hoy conocemos este resultado radiocarbónico (comunicación verbal del Lic. Miguel González del INGEIS) que dió una fecha coetánea con la actualidad, por lo que deberemos replantear nuestra hipótesis.
} 
En el filo próximo al macizo del Tambillos hallamos un conjunto de piedras - aprox. $4.200 \mathrm{~m}$. s. n.m- cuya disposición denuncia la acción humana. No encontramos, sin embargo, restos culturales asociados. Finalmente, accedimos a una de las cumbres menores del Tambillos (la más suroccidental; aprox. 5.000 m. s.n.m.; cumbre por Seufferheld-Clement-D. E. Bonadé, grupo de apoyo Ibarra-R. R. Mons), que no había sido escalada antes (se denominó CRIUNC, por las entidades patrocinantes del proyecto), cuya prospección no dió resultados positivos (fig. 10).

Por otra parte, comenzamos la prospección arqueológica de altura en sectores del mismo Cordón del Tigre pero próximos al tambo de Ranchillos. El objetivo en este caso es la llamada "Cumbre de Yalguaraz", un cordón con varios cerros (los Dientitos, Grande, etc.) que no sobrepasan los $5.200 \mathrm{~m}$. y ubican unos $20 \mathrm{~km}$. al sur del $\mathrm{C}^{\circ}$ Tambillos.

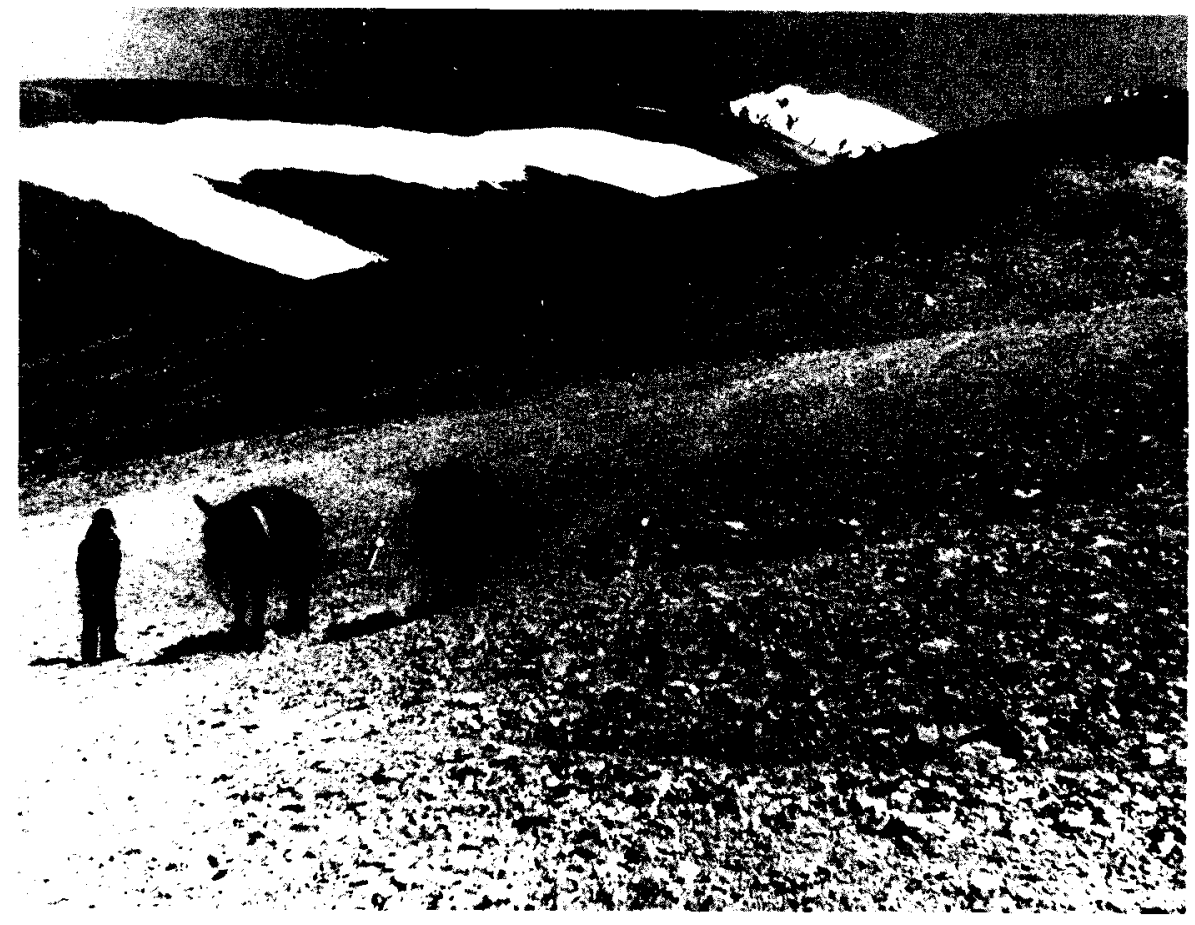

Fig. 10. Cordón del Tigre (Cordillera Frontal) a aprox. 3.750 m. s.n.m. En primer plano la pirca de altura, al fondo el C Tambillos (c. 5.600 m.s.n.m.) con su cima y flanco ocupadas por un notable glaciar. Arriba, a la derecha, se alcanza a divisar la cumbre del $C^{\circ}$ Lira, el $C^{\circ}$ CRIUNC ubica a la izquierda y en un plano más bajo que el Tambillos y no se alcanza a divisar. 


\section{AVANCES DEL PROYECTO}

En lugar de "conclusiones" preferimos sintetizar los siguientes avances de la investigación, según las diversas actividades de campo y gabinete, cumplidas en un marco teórico explícito:

a) Relevamiento total del tambo de Tambillos.

b) Descubrimiento de nuevos recintos en el mismo.

c) Constatación de errores en trabajos parciales anteriores.

d) Hipótesis sobre funcionalidad diferencial de distintas estructuras del tambo. Contrastación de las mismas.

e) Determinación precisa del paso del camino incaico entre los recintos.

f) Hipótesis sobre la jerarquización arquitectónica del sitio. Contrastación con otros tambos de la región. Hipótesis sobre el rol de los mismos en la organización político-administrativa incaica.

g) Comprobación de la disposición de estructuras, orientadas según puntos en el horizonte.

h) Hallazgo de tipos cerámicos no registrados hasta ahora en el área. Interpretación de los mismos.

i) Registro de artefactos que sugieren relaciones de comunidades locales con el incario e, incluso, la probabilidad de una ocupación preexistente a la incaica en el lugar.

j) Confirmación de la ocupación de Tambillos por Mitmakuna del Norte Chico chileno.

k) Determinación precisa del camino incaico en el sector estudiado. Señalamiento del mismo. Descubrimiento de determinadas características técnicas. Contrastación y validación de hipótesis.

1) Prospecciones intensivas de altura con resultados promisorios.

m) Transferencia de los resultados al medio en proceso.

n) Apertura del proyecto para la formación de recursos humanos en la especialidad.

o) Formación de un equipo de trabajo homogéneo. Auxilio multidisciplinario. 


\section{BIBLIOGRAFÍA}

Ampuero B., G., 1969: “Pulidores de cerámica». Boletín del Museo Arqueológico de la Serena, n. ${ }^{\circ} 13$, págs. 45-48. La Serena.

- 1977-78: "Notas para el estudio de la Cultura Diaguita Chilena". Boletín del Museo Arqueológico de la Serena, n. 16, págs. 111-119. La Serena.

- 1978: Cultura Diaguita. Serie El Patrimonio Cultural Chileno. Colección Culturas Aborígenes. Departamento de Extensión Cultural del Ministerio de Educación. Santiago de Chile. 54 páginas.

Aparicio, F. DE, 1940: "Ranchillos. Tambo del inca en el camino a Chile». Anales del Instituto de Etnografía Americana, I, págs. 245-253. Mendoza.

AVENI, A., 1975: Archaeoastronomy in pre-columbian America. University of Texas Press.

- 1981a: "Archaeoastronomy". En Advances in Archaeological Method and Theory, vol. 4, págs. 1-77 (edit. M.B. Schiffer). Nueva York (Academic Press).

- 1981b: "Horizon astronomy in incaic Cuzco". (Archaeoastronomy in the Americas, edit. R. Williamson), págs. 305-318. Santa Bárbara.

BÁRCENA, J. R., 1974: "Nuevos testimonios de la presencia humana prehistórica en el Noroeste de la Provincia de Mendoza". Actualidad Antropológica $\mathrm{n}^{\circ}$ 15, págs. 5-8. Museo Etnográfico Municipal «Dámaso Arce» e Instituto de Investigaciones Antropológicas. Olavarria, Pcia de Buenos Aires.

- 1977 (1979): “Informe sobre recientes investigaciones arqueológicas en el NO de Mendoza-Argentina (valle de Uspallata y zonas vecinas) (Con especial referencia al período incaico)". Actas del VII Congreso de Arqueología de Chile, vol. II, págs. 661-692. Santiago. 
- 1978: «El camino y tambos incaicos a través de recientes investigaciones arqueológicas en el Noroeste de la Prov. de Mendoza (Valle de Uspallata y zonas vecinas) y Sur de San Juan (zona del Barreal del Leoncito)». Actas del V Congreso de Arqueologia Argentina, tomo II (en prensa). San Juan.

- 1977-78 (1981): “Investigaciones arqueológicas en el NO de la Provincia de Mendoza. (Con especial referencia al período precerámico). Anales de Arqueología y Etnología, tomo XXXII-XXXIII, págs. 75-172. Mendoza.

- 1982: «Sinopsis de investigaciones arqueológicas en el NO de la Provincia de Mendoza: secuencias estratigráficas y cronología absoluta". Boletín, N. ${ }^{\circ} 3$, págs. 65-81. Museo de Ciencias Naturales y Antropológicas «J. C. Moyano". Mendoza.

BARCENA, J. R., RolG, Fidel A. 1981-82 (1982): "Investigaciones arqueológicas en el área puneña de Mendoza, con especial referencia a Tephrocactus andicola (Cactaceae) como nuevo recurso alimentario". Relaciones, tomo XIV, n. 2 NS, pp. 85-107. Buenos Aires.

BARCENA, J. R., Rolg Fidel A. y RolG, Virgilio G., 1985: “Aportes arqueofito-zoológicos para la prehistoria de la provincia de Mendoza: la excavación de Agua de la Tinaja I". Trabajos de Prehistoria, vol. 42, págs. 311-363. Madrid.

BARCENA, J. R., 1988: "Funcionalidad diferencial de las estructuras del tambo de Tambillos: excavación de los recintos 1 y 2 de la Unidad del Sector III'. Ms.

BEORCHIA, A., 1984 (1987): «El enigma de los santuarios indígenas de alta montaña". Revista del CIADAM, N. ${ }^{\circ}$ 5, 410 págs. San Juan.

Berberian, E. E., Martin de Zurita, J. y Dussan Gambetta, J., 1977-78 (1981): «Investigaciones arqueológicas en el yacimiento incaico de Tocota (Prov. de San Juan, Rep. Argentina)". Anales de Arqueología y Etnologia, tomo XXXII-XXXIII, págs. 173-210. Mendoza.

BIBAR, G. DE, 1558 (1966): “Crónica y relación copiosa y verdadera... de los Reynos de Chile...". "Fondo histórico y bibliográfico J. T. Medina". Santiago de Chile. (Tomo II, 232 págs.).

Cigliano, E. M. (edit), 1973: Tastil, una ciudad preincaica argentina. Ed. Cabargón, Buenos Aires, 694 páginas.

DauelsberG, P., 1961 (1972): “La cerámica de Arica y su situación cronológica". Chungara, n. 1 , págs. 15-26. Univ. del Norte. Arica (Reimpresión del trabajo presentado a la Mesa Redonda de Arica, 1961).

Durán Serrano, E., 1979 (1982): “El Complejo Cultural Aconcagua y su material ergológico". Actas del VIII Congreso de Arqueología, págs. 5-18. Ediciones Kultrún Ltda. Santiago de Chile. 
Durán Serrano, E. y Massone M., 1977 (1979): «Hacia una definición del Complejo Cultural Aconcagua y sus tipos cerámicos". Actas del VII Congreso de Arqueología Chilena, Vol. 1, págs 243-245. Ediciones Kultrún Ltda. Santiago de Chile.

Duviols, P., 1986: Cultura andina y represión. Procesos y visitas de idolatrias y hechicerias. Cajatambo, siglo xvi. Centro de estudios rurales andinos "Bartolomé de Las Casas". Archivos de Historia Andina, 5. Cuzco.

GonzÁlez, A. R., 1982: “Las "Provincias" Incas del antiguo Tucumán». Revista del Museo nacional, Vol. XLVI, págs 317-380. Lima.

HYSLOP, J., 1979: «El área Lupaca bajo el dominio incaico. Un reconocimiento arqueológico». Revista Histórica, Vol. III, N. ${ }^{\circ}$ I, págs. 53-79. Lima.

- 1984: The inka road system. Studies in Archaeology. Academic Press, Inc. Orlando, Florida, 377 páginas.

- 1985: Inkawasi the New Cuzco. Cañete, Lunahuaná, Perú. BAR International Series 234, 147 páginas.

IRIBARREN, J. y BERGHOLZ, H., 1972: “El camino del inca en un sector del Norte chico". Colección 11 de julio. Compañía de Cobre Salvador, págs. 5-50. Postrerillos, Chile.

KENDALL, A., 1976: “Descripción e inventario de las formas arquitectónicas inca. Patrones de distribución e inferencias cronológicas". Revista del Museo Nacional, tomo XLII, págs. 13-96. Lima.

Krapovickas, P., 1958-59: "Un taller de lapidario en el Pucará de Tilcara». Runa, vol. IX, partes 1-2, págs. 137-151. Buenos Aires.

LAGIGLIA, H., 1976 (1978): “La Cultura de Viluco del Centro Oeste argentino". "Actas y Memorias. IV Congreso Nacional de Arqueología Argentina (Primera Parte)". Revista del Museo de Historia Natural de San Rafael (Mendoza), tomo III (1/4), págs. 227-265. Mendoza.

LizarRaga, Reginaldo de (Fray), 1589? (1916): «Descripción breve del reino del Perú, Tucumán, Río de la Plata y Chile». En: Ricardo Rojas, Descripción colonial, 2 vols., Buenos Aires.

LLAGOSTERA M., A., 1976: "Hipótesis sobre la expansión incaica en la vertiente occidental de los Andes Meridionales". Tomo Homenaje al Dr. Gustavo Le Paige, págs. 203-218. Universidad del Norte, Chile.

LORANDI, A. M., 1977: "Arqueología y etnohistoria: hacia una visión totalizadora del mundo andino». Obra del Centenario del Museo de La Plata, tomo II, págs. 27-50. La Plata.

- 1984: "Soñocamayoc. Los olleros del Inka en los centros manufactureros del Tucumán». Revista del Museo de La Plata, NS, tomo VIII. La Plata. 
MASSONE M., M., 1980: "Nuevas consideraciones en torno al Complejo Aconcagua". Revista chilena de Antropología, n. ${ }^{\circ} 3$, págs. 75-85. Universidad de Chile, Santiago.

MICHIELI, C. T., 1983: Los Huarpes protohistóricos. Instituto de Investigaciones Arqueológicas y Museo. Facultad de Filosofía, Humanidades y Arte, Universidad Nacional de San Juan. 215 páginas.

MorRis, C., 1973: "Establecimientos estatales en el Tawantinsuyu: una estrategia de urbanismo obligado". Revista del Museo Nacional, tomo XXXIX, págs. 127-141. Lima.

- 1974: “El muestreo en la excavación de sitios incaicos. El caso de Huánuco Pampa". Revista del Museo Nacional, tomo XL, págs. 111113. Lima.

- 1981: «Tecnología y organización inca del almacenamiento de viveres en la Sierra". En: H. Lechtman y A.M. Soldi, edits.; La Tecnología en el mundo andino, vol. 1, págs. 327-375. UNAM, México.

Munizaga, C., 1957: "Secuencias culturales de la zona de Arica". Centro de Estudios Antropológicos de la Universidad de Chile, $n .^{\circ}$ 2, págs. 77-122+lám. Santiago.

MurRA, J., 1967-68 (1970): "Investigaciones y posibilidades de la etnohistoria andina en la actualidad". Revista del Museo Nacional, tomo XXXV, págs. 125-159. Lima.

- 1975: Formaciones económicas y politicas del mundo andino. «Historia andina", 3.IEP. 339 págs. Lima.

NiemeYer F., H., 1963-1964: "Excavación de un cementerio incaico en la Hacienda Camarones (Prov. de Tarapacá)». Revista Universitaria, tomo XLVIII, págs. 207-224 (+Apéndice, págs. 225-233). Santiago de Chile.

- 1969-70: «El yacimiento arqueológico de Huana (Dpto. Ovalle, Prov. Coquimbo, Chile)". Boletín de Prehistoria, 2-3, págs. 3-63. Santiago de Chile.

Olivera, D. E., lacona, L. A., Raviña, G. M., Baldini, L. y Alvis, R. J., 1981 (1982): Los inkas del Kollasuyu. Ramos Americana Editora, La Plata-Buenos Aires, 301 páginas.

Raffino, R. A., Albornoz, A. M., Bucci, A. L., Crowder, R., lácona, A., OliverA, D. E. y RAviña, G., 1978 (179): «La ocupación inka en el NO argentino: actualización y perspectivas». Relaciones, NS, tomo XII, págs. 95-121. Buenos Aires.

Raviña, G., lácona, L. A., Olivera, D. E. y Albornoz, A. M., 1979-82: "Aplicaciones de la teoría de sistemas y propuesta taxonómica de los vestigios inka en los Andes meridionales". Cuadernos del Instituto Nacional de Antropología, vol. 9, págs. 59-76. Buenos Aires. 
REINHARD, J., 1985: «Sacred mountains: an ethno-archaeological study of high andean ruins». Mountain Research and Development, vol. $5, \mathrm{n}^{\circ}$ 4, págs. 299-317.

Relaciones Geográficas de Indias, tomo II, Perú. Ministerio de Fomento. Madrid, 1885 (siglo XVI)

Rusconi, C., 1956: "La ciudadela prehispánica de Ranchillos (Mendoza)". Revista del Museo de Historia Natural de Mendoza, vol. IX, entregas 1 y 2, págs. 55-87 más XII láminas. Mendoza.

- 1962: Poblaciones pre y posthispánicas de Mendoza. Tomo III, "Arqueología». Mendoza, 623 páginas.

RYDEN, S., 1947: "Archaeological researches in the Highlands of Bolivia». Göteborg.

SCHOBInGer, J. (edit.), 1966: La "Momia" del C El Toro. Investigaciones arqueológicas en la cordillera de la provincia de San Juan (República Argentina). Suplemento del tomo XXI de los «Anales de Arqueología y Etnología», Mendoza, 218 páginas.

- 1971: "Arqueología del Valle de Uspallata, Provincia de Mendoza. (Sinopsis preliminar)». Relaciones, NS, tomo $\mathrm{V}, \mathrm{n} .{ }^{\circ} 2$, págs 71-84. Buenos Aires.

- 1986: "La red de santuarios de alta montaña en el Contisuyo y el Collasuyu: evaluación general, problemas interpretativos". Comechingonia, Revista de Antropología e Historia, n. ${ }^{\circ}$ especial, págs 295-317. Córdoba.

- y BÁRCENA, J. R., 1971 (1972-73): “El 'tambo' incaico de Tambillitos (Prov. Mendoza, Argentina)". Actas del VI Congreso de Arqueología Chilena, págs. 397-403. Santiago de Chile.

- y BárCenA, J. R., 1972: “El 'tambo' incaico de Tambillitos". Revista Autoclub, n. ${ }^{\circ} 62$, enero-febrero, págs. 106-109. Buenos Aires.

- y BÁRCENA, J. R., 1982: Reedición de 1971 (1972-73). En “Estudios de arqueología sudamericana». Ediciones Castañeda, Buenos Aires.

Segovia A., M., 1959: "Cementerio indígena en el Puerto de Huasco". Boletín n. ${ }^{\circ} 10$, págs. 45-54 más láminas. Publicaciones del Museo y de la Sociedad Arqueológica de La Serena.

Stehberg L., R., 1981: «El complejo prehispánico Aconcagua en la Rinconada de Huechún". Publicación Ocasional, n. ${ }^{\circ} 35$, Museo Nacional de Historia Natural. 87 páginas

ZUIDEMA, R. T., 1966 (1968): «La relación entre el patrón de poblamiento prehispánico y los principios derivados de la estructura social incaica". XXXVII CIA, Actas y Memorias del..., vol. 1, págs. 45-55. Buenos Aires. 